\title{
BMJ Open Multimorbidity as an important issue among women: results of a gender difference investigation in a large population-based cross-sectional study in West Asia
}

Masoomeh Alimohammadian, ${ }^{1,2,3}$ Azam Majidi, ${ }^{2,3}$ Mehdi Yaseri, ${ }^{4}$ Batoul Ahmadi, ${ }^{5}$ Farhad Islami, ${ }^{2,6}$ Mohammad Derakhshan, ${ }^{3,7}$ Alireza Delavari, ${ }^{2,3}$ Mohammad Amani, ${ }^{2,3}$ Akbar Feyz-Sani, ${ }^{2,3}$ Hossein Poustchi, ${ }^{2,3}$ Akram Pourshams, ${ }^{2,3,8}$ Amir Mahdi Sadjadi, ${ }^{2}$ Masoud Khoshnia, ${ }^{3,9}$ Samad Qaravi, ${ }^{3,9}$ Christian C Abnet, ${ }^{10}$ Sanford Dawsey, ${ }^{10}$ Paul Brennan, ${ }^{11}$ Farin Kamangar, ${ }^{2,12}$ Paolo Boffetta, ${ }^{13}$ Alireza Sadjadi, ${ }^{2,3}$ Reza Malekzadeh ${ }^{2,3}$

To cite: Alimohammadian $\mathrm{M}$, Majidi A, Yaseri M, et al. Multimorbidity as an important issue among women: results of a gender difference investigation in a large population-based cross-sectional study in West Asia. BMJ Open 2017;7:e013548. doi:10.1136/ bmjopen-2016-013548

- Prepublication history and additional material are available. To view please visit the journal (http://dx.doi.org/ 10.1136/ bmjopen-2016-013548).

$B A$ and $A S$ contributed equally.

MA and AM contributed equally.

Received 20 July 2016 Revised 11 February 2017 Accepted 10 March 2017

\section{CrossMark}

For numbered affiliations see end of article.

\section{Correspondence to}

Batoul Ahmadi;

ahmadiba@tums.ac.ir and Dr Alireza Sadjadi; sadjadia@gmail. com

\section{ABSTRACT}

Objectives To investigate the impact of gender on multimorbidity in northern Iran.

Design A cross-sectional analysis of the Golestan cohort data.

Setting Golestan Province, Iran.

Study population 49946 residents (age 40-75 years) of Golestan Province, Iran.

Main outcome measures Researchers collected data related to multimorbidity, defined as co-existence of two or more chronic diseases in an individual, at the beginning of a representative cohort study which recruited its participants from 2004 to 2008 . The researchers utilised simple and multiple Poisson regression models with robust variances to examine the simultaneous effects of multiple factors.

Results Women had a $25.0 \%$ prevalence of multimorbidity, whereas men had a $13.4 \%$ prevalence $(p<0.001)$. Women of all age-groups had a higher prevalence of multimorbidity. Of note, multimorbidity began at a lower age (40-49 years) in women (17.3\%) compared with men $(8.6 \%)$ of the same age $(p<0.001)$. This study identified significant interactions between gender as well as socioeconomic status, ethnicity, physical activity, marital status, education level and smoking $(p<0.01)$. Conclusion Prevention and control of multimorbidity requires health promotion programmes to increase public awareness about the modifiable risk factors, particularly among women.

\section{INTRODUCTION}

Chronic diseases not only induce physical complications and social hardships for patients, but also present a heavy burden for healthcare systems. This issue can be further intensified by multimorbidity, the simultaneous occurrence of two or more chronic

\section{Strengths and limitations of this study}

- This is a large, population-based crosssectional study, with detailed data provided on sociodemographic, lifestyle and behavioural risk factors.

- Trained, qualified medical researchers collected all of the data by interactive face-to-face interviews.

- Cross-sectional data analyses are susceptible to residual confounding and cannot determine the direction of an association.

- Another limitation of this investigation was possible recall bias resulting from the method of gathering medical history (self-report).

diseases in one person. ${ }^{1-3}$ Multimorbidity is associated with a higher mortality risk and increased utilisation of healthcare services; therefore, it is a demanding situation for patients, their families and healthcare providers. $^{4-8}$

Despite the increase in life expectancy among lower and middle income countries over the last decades, the growing prevalence of multimorbidity has led to a decreased quality of life in patients with chronic diseases, especially in populations with limited resources. ${ }^{9} 10$ Patients with multimorbidity require specific medical care; however, the current clinical practice lacks practical guidelines to manage and treat these patients. ${ }^{1-14}$ Current clinical practices for patients with multiple chronic diseases routinely deal with each individual disease rather than multiple diseases, and can result in increased expenses for patients 
and healthcare systems, and possibly lead to unwanted adverse effects. ${ }^{13} 1516$

Previous studies have shown a gender difference in patterns of multimorbidity. A systematic review of most previous studies indicated that women had a greater prevalence of multimorbidity compared with men. ${ }^{17}$ This difference might be related to biological, sociocultural, environmental or economic factors. As these factors vary globally, their associations with multimorbidity might differ across populations. ${ }^{18-22}$ Therefore, more research should be conducted on this topic.

We used baseline data from the Golestan Cohort Study (GCS), a large-scale prospective study in Western Asia, to explore the epidemiology of multimorbidity. ${ }^{23}$ In this article we used detailed statistical analyses to examine the variability of the prevalence and determinants of multimorbidity among different age groups. We also investigated interactions between gender and multiple sociodemographic and lifestyle factors potentially associated with multimorbidity.

\section{METHODS}

This cross-sectional study analysed baseline data from the GCS. We analysed data from 49946 Iranians, aged 40-75 years, who resided in Golestan Province in northeastern Iran. Participants had no current or previous diagnosis of any upper gastrointestinal cancers. The original cohort recruited its participants from 2004 to $2008 .{ }^{24}$ The details of this study have been described elsewhere. ${ }^{23}$

Body mass index (BMI) was defined as underweight $\left(<18.5 \mathrm{~kg} / \mathrm{m}^{2}\right)$, normal $\left(18.5-24.9 \mathrm{~kg} / \mathrm{m}^{2}\right)$, overweight $\left(25-29.9 \mathrm{~kg} / \mathrm{m}^{2}\right)$, and obese $\left(>30 \mathrm{~kg} / \mathrm{m}^{2}\right)$. We divided participants into the following age clusters (age at the time of the interviews): $40-49,50-60$, and $61-75$ years. In this mainly rural population, physical activity was defined based on occupational activity as follows: physically active (heavy or intense activity during employment) or physically inactive (all other participants). Participants' socioeconomic status (SES) comprised three levels (low, middle or high) according to the two-step cluster anal$\mathrm{ysis}^{25}$ with the use of similarities for family assets, ethnicity, sex, employment status, age at onset of the first job, home ownership status and house size (surface area), and age.

Based on the possibility of gathering valid self-reported data during the feasibility phase of the GCS, we collected self-reported information for the following chronic diseases: cardiovascular disease, diabetes (types I and II), chronic obstructive pulmonary disease, chronic kidney disease, chronic liver disease, tuberculosis, gastro-oesophageal reflux disease (GORD), and cancers. ${ }^{24}$ Respondents reported the presence of regurgitation or heartburn during the past 1-2 years, via a standard GORD questionnaire. ${ }^{26}{ }^{27}$ Participants who reported any symptoms during the mentioned time period were considered to have GORD.

In this study, we defined multimorbidity as the simultaneous occurrence of two or more of the above mentioned chronic diseases (non-acute conditions) ${ }^{23}$ in the same person. ${ }^{7828}$

\section{Statistical analysis}

We estimated multimorbidity among participants according to several sociodemographic and lifestyle factors. The Student's t-test, Mann-Whitney or $\chi^{2}$ tests evaluated differences in the distribution of respondents according to sociodemographic factors and lifestyle factors between men and women whenever appropriate.

Occasions exist in which the OR can be misleading. Hence, we have used a model that could provide the prevalence ratio. Simple and multiple Poisson regressions were used with robust variances according to the method presented by Barros and Hirakata. ${ }^{29}$ We sought to examine the possibility of a gender-based association between the studied factors and multimorbidity, calculated crude and adjusted prevalence ratios and tested it with the interaction (effect modification) test, and 95\% CIs. The gender differences between determinants of multimorbidity (ie, interaction or effect modification) were evaluated in separate multiple Poisson regression models.

We have considered the design effects according to the generalised estimating equations method for all analyses. This method is a generalisation of the generalized linear model (GLM) that can handle the correlation of observation. The assumption of the GLM is the independence of observation which could be violated in studies that have intra-cluster correlations in cluster sampling or randomisation, as well as in longitudinal analysis of repeated measurements obtained from a subject. ${ }^{30}{ }^{31}$ All statistical analyses were performed using SPSS software (IBM Corporation, released 2013, IBM SPSS Statistics for Windows, version 22.0; Armonk, New York, USA). Two-sided p-values $<0.05$ were considered statistically significant.

\section{RESULTS}

This cross-sectional study enrolled 49946 participants (aged 40-75 years) who predominantly resided in rural areas. Women comprised 28748 (57.6\%) participants. The Supplementary table shows the prevalence of self-reported chronic diseases in those with multimorbidity and the gender differences.

The results indicated an overall age-sex standardised prevalence for multimorbidity of $19.4 \%$ (95\% CI $19.1 \%$ to $19.8 \%)$. Women had almost twice the prevalence $(25.0 \%)$ compared with men $(13.4 \%)$, with a difference of $11.7 \%$ $(95 \%$ CI $11.0 \%$ to $12.4 \%) \quad(\mathrm{p}<0.001)$. Table 1 shows the prevalence of multimorbidity in all study participants according to gender, sociodemographic and lifestyle factors. Women had evidence of more multimorbidity in all age groups. Of note, compared with men, multimorbidity in women began at an earlier age (40-49 years). In this age group, $17.3 \%$ of women had multimorbidity compared with $8.6 \%$ for men $(\mathrm{p}<0.001)$. 


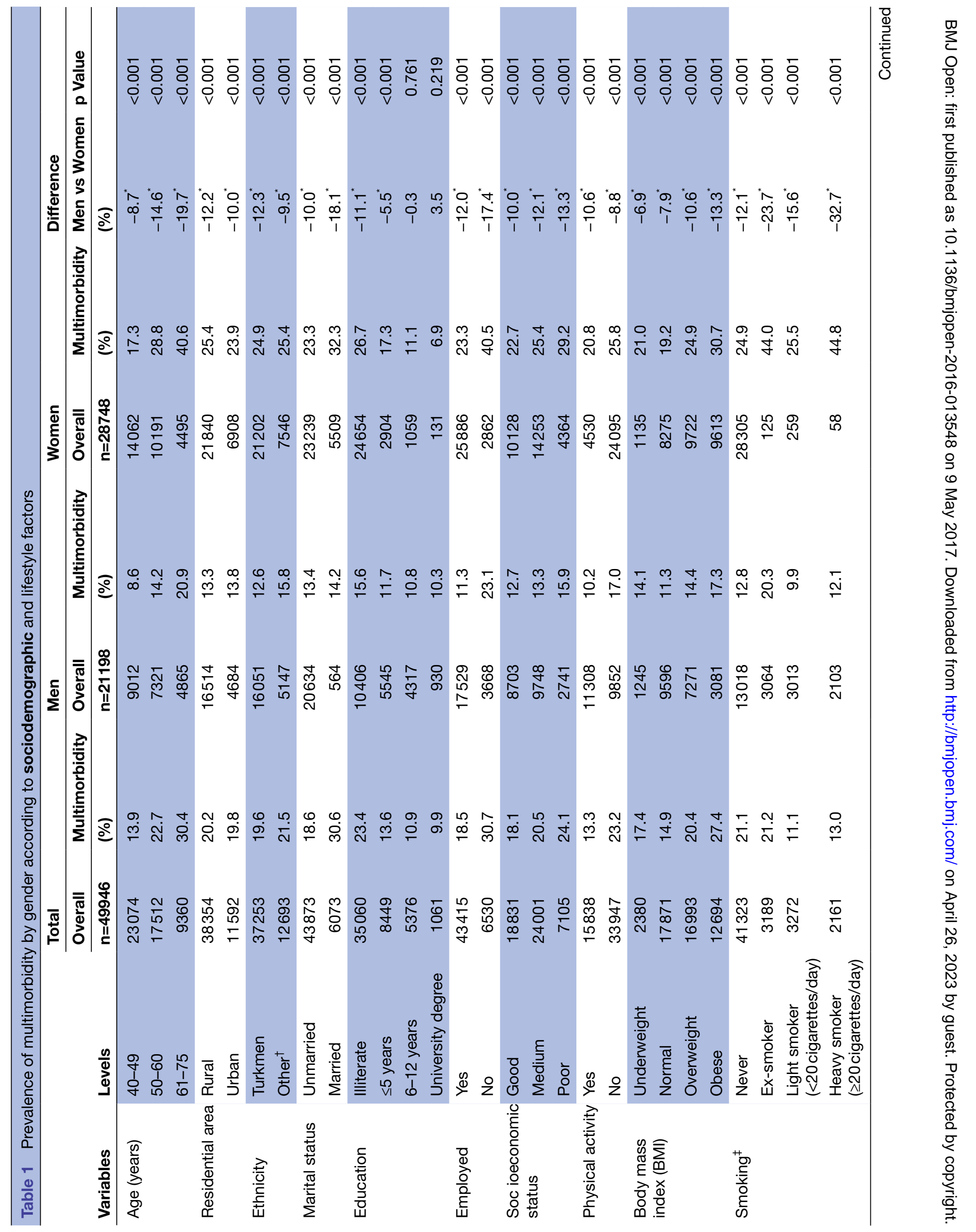




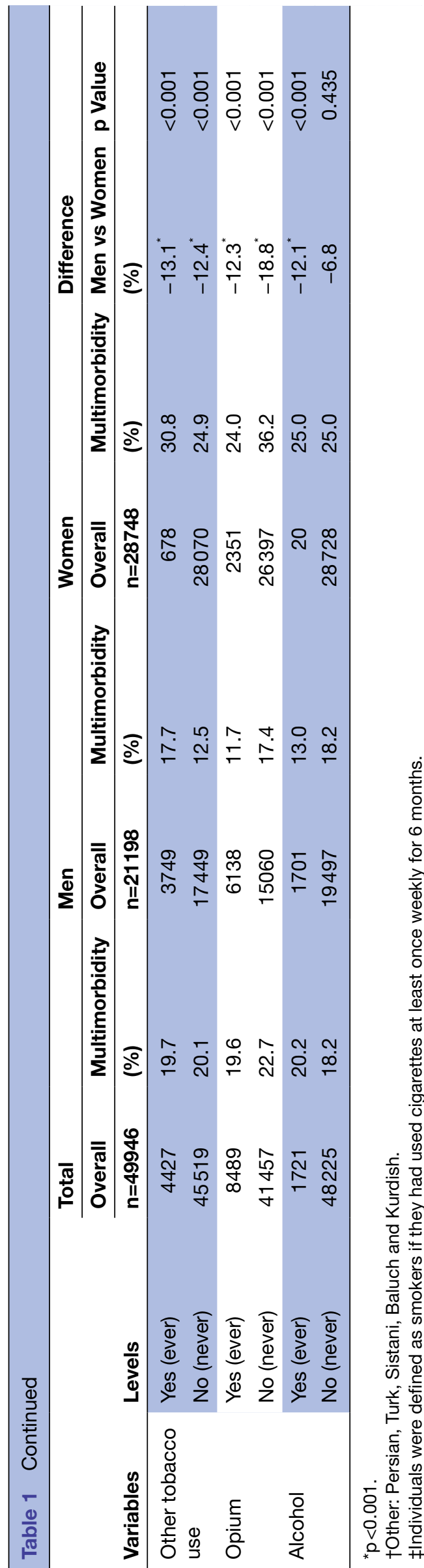

Table 2 shows the results from multiple Poisson regression models. Men who were ex-smokers, non-Turkmen, married and physically inactive had a significantly higher chance of multimorbidity. Being in lower socioeconomic groups showed an association with multimorbidity only in women. Higher educational levels (compared with illiteracy) showed an inverse association with multimorbidity, mainly in women $(p<0.001)$. Based on interaction analysis, a significantly stronger association existed between poor/middle SES with multimorbidity in women compared with men $(\mathrm{p}=0.033)$. The associations between non-Turkmen ethnicity groups $(\mathrm{p}=0.003)$, married status $(\mathrm{p}=0.041)$, physical inactivity $(\mathrm{p}=0.009)$ and ex- smoking $(p=0.033)$ and the prevalence of multimorbidity was statistically significant in men only, or stronger in men compared with women. There was an inverse association between education and multimorbidity mainly in women ( $p$ for interaction $<0.001$ ).

\section{DISCUSSION}

This study examined gender-related determinants of multimorbidity in a cross-sectional analysis of a large cohort study that had more than 49000 participants. Women of all ages had a higher overall prevalence of multimorbidity. Multimorbidity was not only prevalent in elderly people, it also affected participants aged 40-49 years. Gender interacted with sociodemographic factors of ethnicity, marital status, educational level, SES, physical activity and smoking in terms of multimorbidity prevalence. Past smoking history, non-Turkmen ethnic groups, married status and physical inactivity showed significant associations with multimorbidity in men. Lower socioeconomic groups were associated with multimorbidity, but only in women.

Despite current perceptions, this study revealed that multimorbidity was not confined to elderly people. The results showed that middle-age cohort participants (age $<50$ ) of both genders also suffered from this condition, and this observation has been supported by another study. ${ }^{32}$ We observed that women had a greater burden of multimorbidity which supported the results from a study by Zielinski $e t$ al on a Swedish population. ${ }^{33}$ A potential cause for more significant prevalence of multimorbidity among women could be their relatively higher tendency to share their conditions in self-reports. ${ }^{34} 35$ There is evidence that women use more healthcare facilities, particularly public funded healthcare, compared with men. ${ }^{36-38}$ Possible influences for this excess multimorbidity in women could be higher exposure to common risk factors for chronic diseases or gender inequality in access to healthcare. ${ }^{78-42}$ It is worth mentioning that this information is related to data collected approximately 10 years ago at a subnational level.

This study showed a significant association between low SES and multimorbidity among women, a finding suggested by earlier studies. ${ }^{43}$ This might partially be explained by differences in lifestyle attributed to SES. Low 


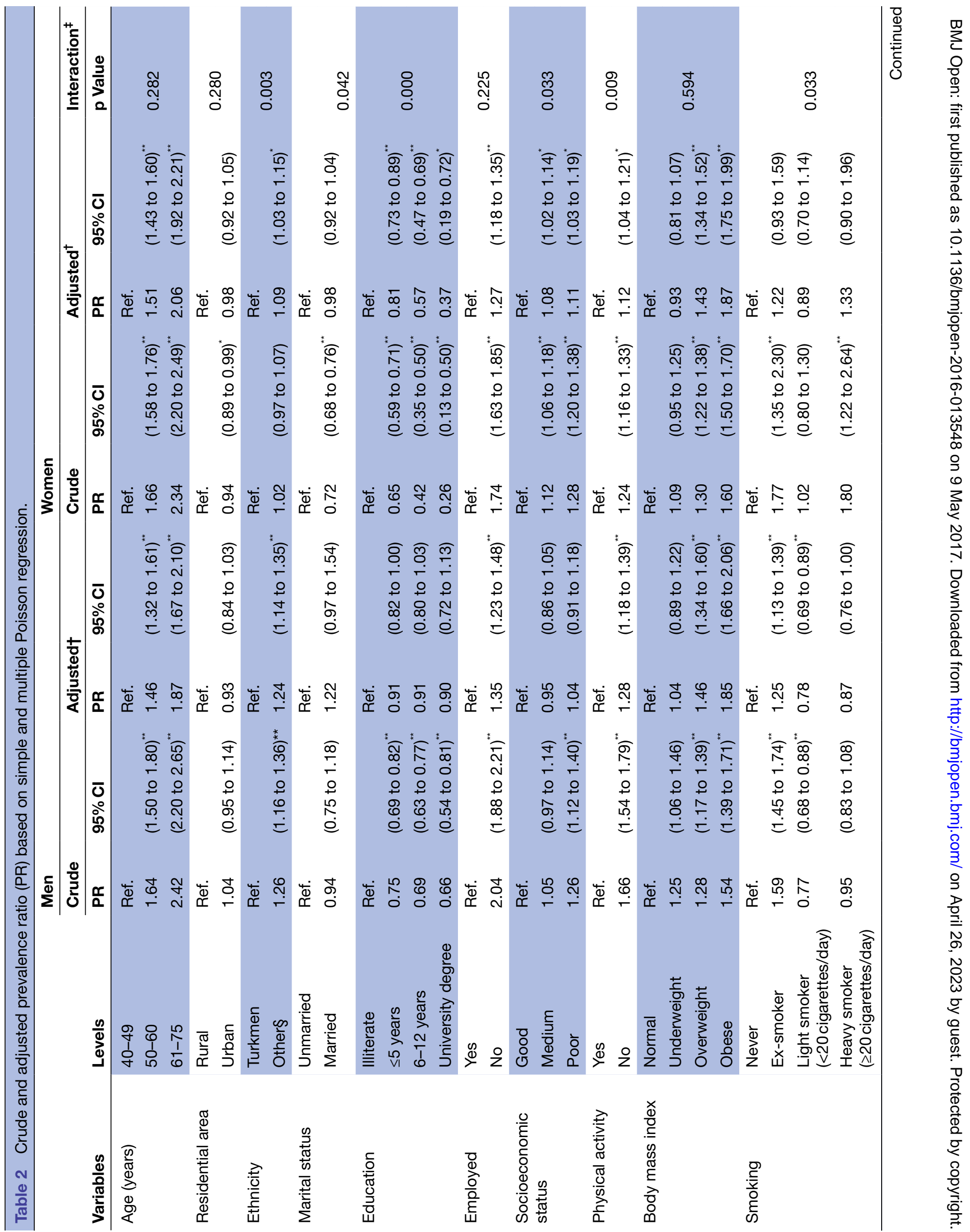




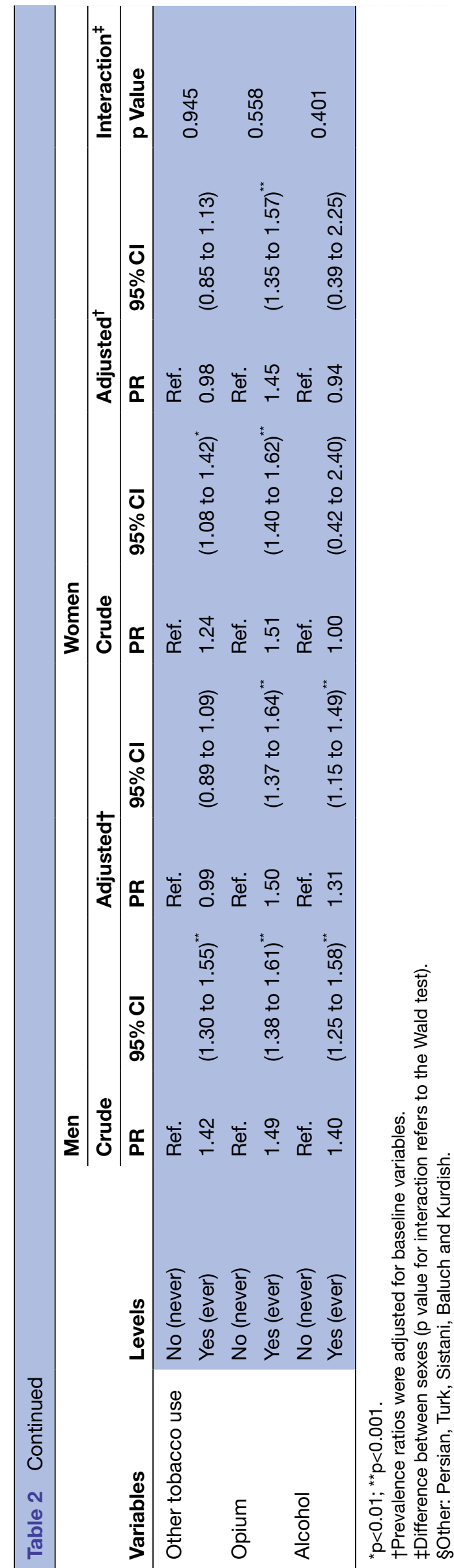

SES might reduce care-seeking in patients with chronic diseases. ${ }^{43}$ This might produce a paradox, as lower healthcare use might translate to lower documented morbidity. This study's findings indicated that low and middle SES had an association with multimorbidity in women, which has supported the assertion that women are at higher risk from the adverse effects of poverty, payment inequality and health disparities. ${ }^{45}$ Khanam et al concluded that gender differences in SES, living and working environments, lifestyle factors and life-events might affect the occurrence and outcome of multimorbidity among women. ${ }^{46}$

A previous study revealed that inactivity might increase the risk of breast and colorectal cancers, diabetes mellitus and ischaemic heart diseases. ${ }^{47}$ Autenrieth et al discovered an inverse association between physical activity and multimorbidity among men..$^{35}$ Another study reported no association between multimorbidity and physical activity for either men or women. ${ }^{48}$ We observed an association between sedentary occupations that involved decreased physical activity and multimorbidity, which was more evident in men. This might be due to the proportionately longer hours that men spend in sedentary occupations.

In this study the prevalence ratio of multimorbidity significantly decreased with increased education level; the association was more obvious in women. Similarly, other studies showed a decreased likelihood of multimorbidity among better-educated populations. ${ }^{39} 4249$

The GCS enrolled participants above 40 years of age whose cultural, educational and social basis was shaped around the 1970s - a time of limited access to primary healthcare facilities, particularly in rural areas. ${ }^{50}$ However, after the 1980s, there was a substantial improvement in health, life expectancy, control of communicable diseases and SES in Iran. ${ }^{25} 50$ Iran was among the few countries that reached WHO defined millennium development goals before 2015. ${ }^{51}$ We observed that education was defined as a protective factor for multimorbidity. In this population, women had a literacy rate below $20 \% .{ }^{24}$ The latest report, released in 2014, has shown a tremendous increase in women's literacy in Golestan Province, which is over $80 \% .^{52}$ The improvements in health, education and other SES have decreased health inequalities which may influence disease patterns, including multimorbidity, in succeeding generations.

Access to affordable health services, as a human right, is a necessity for improved quality of life. Despite the considerable progress in community health in recent decades, there is an increasing prevalence of chronic diseases. ${ }^{53}$ Some global movements related to healthy lifestyles have underlined the need for multi-dimensionality collaborations for health promotion as stated in the Ottawa Charter. ${ }^{53-57}$ The findings of this study and recommendations by $\mathrm{WHO}^{53}$ indicate that specific national and sub-national health policies for men and women of different age groups and SES should be implemented.

The possible changes in demographic characteristics and lifestyle habits of the Iranian population over the past decades and the current study sampling methods 
(regional vs national) should be taken into consideration. Future studies that assess more representative samples or at the national level are recommended.

\section{CONCLUSION}

The findings of this study confirm that multimorbidity is an important health issue for all individuals above 40 years of age, with particular emphasis on women with lower SES and educational levels. Men with decreased physical activity who are married and are former smokers also have a higher risk for multimorbidity.

Defining priority interventions and multisectorial policies that tackle multimorbidity in both men and women, as well as focusing increased attention on middle-aged populations, are required. In order to control multimorbidity, particularly in women, we recommend the use of health promotion and educational methods to enhance public awareness about modifiable risk factors such as physical activity and smoking.

\section{Author affiliations}

${ }^{1}$ Department of Human Ecology, School of Public Health, Tehran University of Medical Sciences, Tehran, Islamic Republic of Iran

${ }^{2}$ Digestive Diseases Research Center, Digestive Diseases Research Institute, Tehran University of Medical Sciences, Tehran, Islamic Republic of Iran

${ }^{3}$ Digestive Oncology Research Center, Digestive Diseases Research Institute, Tehran University of Medical Sciences, Tehran, Islamic Republic of Iran

${ }^{4}$ Department of Epidemiology and Biostatistics, School of Public Health, Tehran University of Medical Sciences, Tehran, Islamic Republic of Iran

${ }^{5}$ Department of Health Management and Economics, School of Public Health, Tehran University of Medical Sciences, Tehran, Islamic Republic of Iran

${ }^{6}$ Surveillance and Health Service Research, American Cancer Society, Atlanta, GA, USA

${ }^{7}$ Section of Gastroenterology, Division of Cardiovascular and Medical Sciences, University of Glasgow, Glasgow, UK

${ }^{8}$ Liver and Pancreatic Biliary Research Center, Digestive Diseases Research Institute, Tehran University of Medical SCiences, Tehran, Islamic Republic of Iran ${ }^{9}$ Golestan Research Center of Gastroentreology and Hepatology, Golestan University of Medical Sciences, Gorgan, Golestan, Islamic Republic of Iran

${ }^{10}$ Division of Cancer Epidemiology and Genetics, National Cancer Institute, National Institutes of Health, Bethesda, Washington, MD, USA

${ }^{11}$ Genetic Epidemiology Group, International Agency for Research on Cancer, Lyon, France

${ }^{12}$ Department of Public Health Analysis, School of Community Health and Policy, Morgan State University, Baltimore, USA

${ }^{13}$ Mount Sinai School of Medicine, The Tisch Cancer Institute, New York, NY, USA

Acknowledgements We wish to thank the study participants for their cooperation over a number of years and the primary healthcare workers (Behvarz) employed in the study areas for their help.

Contributors MY analysed the data. MA, AM, BA, AS, MY, AMS and RM, drafted the manuscript. AS, AM, MA, AFS, and MHD provided scientific input. RM, AP, HP, $S Q, M K, A D$, and MA provided expert clinical advice and data interpretation. RM, $\mathrm{PB}, \mathrm{FK}, \mathrm{BA}, \mathrm{CCA}, \mathrm{SD}, \mathrm{AP}, \mathrm{FI}, \mathrm{PB}$, and SMD provided expert guidance on health policy and delivery of healthcare and interpretation of the data. RM, AS, MA, AM, BA, MY, $\mathrm{FK}, \mathrm{SD}, \mathrm{PB}, \mathrm{PB}, \mathrm{MHD}, \mathrm{CCA}$, and $\mathrm{FI}$ were involved as methodologists in research interpretation and manuscript writing. All authors made critical revisions and provided intellectual content to the manuscript, approved the final version to be published, and agreed to be accountable for all aspects of this work. AS and BA are the guarantors for this study.

Competing interests None declared.

Ethics approval The ethics committee of the Digestive Diseases Research Institute, Tehran University of Medical Sciences (OHRP-IRB-00001641)

Provenance and peer review Not commissioned; externally peer reviewed.
Data sharing statement Data are available and can be accessed by contacting Dr. Alireza Sadjadi (sadjadia@gmail.com)

Open Access This is an Open Access article distributed in accordance with the Creative Commons Attribution Non Commercial (CC BY-NC 4.0) license, which permits others to distribute, remix, adapt, build upon this work non-commercially, and license their derivative works on different terms, provided the original work is properly cited and the use is non-commercial. See: http://creativecommons.org/ licenses/by-nc/4.0/

(C) Article author(s) (or their employer(s) unless otherwise stated in the text of the article) 2017. All rights reserved. No commercial use is permitted unless otherwise expressly granted.

\section{REFERENCES}

1. Loza E, Jover JA, Rodriguez L, et al; EPISER Study Group. Multimorbidity: prevalence, effect on quality of life and daily functioning, and variation of this effect when one condition is a rheumatic disease. Semin Arthritis Rheum 2009;38:312-9.

2. Van den Akker M, Buntinx F, Metsemakers JF, et al. Multimorbidity in general practice: prevalence, incidence, and determinants of co-occurring chronic and recurrent diseases. J Clin Epidemiol 1998;51:367-75

3. Violán C, Foguet-Boreu Q, Roso-Llorach A, et al. Burden of multimorbidity, socioeconomic status and use of health services across stages of life in urban areas: a cross-sectional study. BMC Public Health 2014;14:530.

4. Alaba O, Chola L. The social determinants of multimorbidity in South Africa. Int J Equity Health 2013;12:63.

5. Barnett K, Mercer SW, Norbury M, et al. Epidemiology of multimorbidity and implications for health care, research, and medical education: a cross-sectional study. Lancet 2012;380:37-43.

6. Diederichs CP, Wellmann J, Bartels DB, et al. How to weight chronic diseases in multimorbidity indices? Development of a new method on the basis of individual data from five population-based studies. $J$ Clin Epidemiol 2012;65:679-85.

7. Foguet-Boreu Q, Violan C, Roso-Llorach A, et al. Impact of multimorbidity: acute morbidity, area of residency and use of health services across the life span in a region of south Europe. BMC Fam Pract 2014;15:55.

8. de S Santos Machado V, Valadares AL, Costa-Paiva LH, et al. Aging, obesity, and multimorbidity in women 50 years or older: a population-based study. Menopause 2013;20:818-24.

9. Reza A, Rusk IS, Robab S. Aging in Iran: past, present and future. J Aging Em Economies 2013;4:17-34.

10. WHO- Country Profile. Iran (Islamic Republic of) 2013; 2015. http:// www.who.int/countries/irn/en/ (access 29 Dec 2015).

11. Quiñones AR, Markwardt S, Botoseneanu A. Multimorbidity combinations and disability in older adults. J Gerontol A Biol Sci Med Sci 2016;71:823-30.

12. Boyd CM, Fortin M. Future of multimorbidity research: how should understanding of multimorbidity inform health system design. Public Health Rev 2010;32:451-74.

13. Guthrie B, Payne K, Alderson P, et al. Adapting clinical guidelines to take account of multimorbidity. BMJ 2012;345:e6341.

14. Hughes LD, McMurdo ME, Guthrie B. Guidelines for people not for diseases: the challenges of applying UK clinical guidelines to people with multimorbidity. Age Ageing 2013;42:62-9.

15. Schäfer I, von Leitner EC, Schön G, et al. Multimorbidity patterns in the elderly: a new approach of disease clustering identifies complex interrelations between chronic conditions. PLoS One 2010;5:e15941.

16. Uhlig K, Leff $\mathrm{B}$, Kent $\mathrm{D}$, et al. A framework for crafting clinical practice guidelines that are relevant to the care and management of people with multimorbidity. J Gen Intern Med 2014;29:670-9.

17. Violan C, Foguet-Boreu Q, Flores-Mateo G, et al. Prevalence, determinants and patterns of multimorbidity in primary care: a systematic review of observational studies. PLOS One 2014;9:e102149.

18. WHO. Health topics: women's health: World Health Organization, 2015.

19. Verdonk P, Klinge I. Mainstreaming sex and gender analysis in public health genomics. Gend Med 2012;9:402-10.

20. Goldman MB. Women and health. 2 ed. China: Elsevier/Academic Press, 2013.

21. Ruby TS. An overview of women's health: from the past to the future. Epidemiology of women's health: Jones \& Bartlett Publishers, 2013:3-14. 
22. Vlassoff $C$. Gender differences in determinants and consequences of health and illness. J Health Popul Nutr 2007;25:47-61.

23. Ahmadi B, Alimohammadian M, Yaseri M, et al. Multimorbidity: epidemiology and risk factors in the Golestan cohort study, Iran: a cross-sectional analysis. Medicine 2016;95:e2756.

24. Pourshams A, Khademi H, Malekshah AF, et al. Cohort profile: the Golestan cohort study-a prospective study of oesophageal cancer in northern Iran. Int J Epidemiol 2010;39:52-9.

25. Islami F, Kamangar F, Nasrollahzadeh D, et al. Socio-economic status and oesophageal cancer: results from a population-based casecontrol study in a high-risk area. Int J Epidemiol 2009;38:978-88.

26. Shaw MJ, Talley NJ, Beebe TJ, et al. Initial validation of a diagnostic questionnaire for gastroesophageal reflux disease. Am J Gastroentero/ 2001;96:52-7.

27. Islami F, Nasseri-Moghaddam S, Pourshams A, et al. Determinants of gastroesophageal reflux disease, including hookah smoking and opium use- a cross-sectional analysis of 50,000 individuals. PLOS One 2014;9:e89256.

28. Van Oostrom SH, Picavet HS, van Gelder BM, et al. Multimorbidity and comorbidity in the Dutch population-data from general practices. BMC Public Health 2012;12:715.

29. Barros AJ, Hirakata VN. Alternatives for logistic regression in crosssectional studies: an empirical comparison of models that directly estimate the prevalence ratio. BMC Med Res Methodol 2003;3:1.

30. Eldridge SM, Ashby D, Kerry S. Sample size for cluster randomized trials: effect of coefficient of variation of cluster size and analysis method. Int J Epidemiol 2006;35:1292-300.

31. Hanley JA, Negassa A, Edwardes MD, et al. Statistical analysis of correlated data using generalized estimating equations: an orientation. Am J Epidemiol 2003;157:364-75.

32. Taylor AW, Price K, Gill TK, et al. Multimorbidity - not just an older person's issue. Results from an Australian biomedical study. BMC Public Health 2010;10:718.

33. Zielinski A, Halling A. Association between age, gender and multimorbidity level and receiving home health care: a populationbased Swedish study. BMC Res Notes 2015;8:714.

34. Murtagh KN, Hubert HB. Gender differences in physical disability among an elderly cohort. Am J Public Health 2004;94:1406-11.

35. Autenrieth CS, Kirchberger I, Heier M, et al. Physical activity is inversely associated with multimorbidity in elderly men: results from the KORA-Age Augsburg study. Prev Med 2013;57:17-19.

36. Chen FM, Fryer GE, Norris TE. Effects of comorbidity and clustering upon referrals in primary care. J Am Board Fam Pract 2005;18:449-52.

37. Forrest $\mathrm{CB}$, Nutting PA, von Schrader S, et al. Primary care physician specialty referral decision making: patient, physician, and health care system determinants. Med Decis Making 2006;26:76-85.

38. Bertakis KD, Azari R, Helms LJ, et al. Gender differences in the utilization of health care services. J Fam Pract 2000;49:147-52.

39. Afshar S, Roderick PJ, Kowal P, et al. Multimorbidity and the inequalities of global ageing: a cross-sectional study of 28 countries using the world health surveys. BMC Public Health. 2015;15:1-10.
40. Abad-Díez JM, Calderón-Larrañaga A, Poncel-Falcó A, et al. Age and gender differences in the prevalence and patterns of multimorbidity in the older population. BMC Geriatr 2014;14:75

41. Wang SB, D'Arcy C, Yu YQ, et al. Prevalence and patterns of multimorbidity in northeastern China: a cross-sectional study. Public Health 2015;129:1539-46.

42. St John PD, Tyas SL, Menec V, et al. Multimorbidity, disability, and mortality in community-dwelling older adults. Can Fam Physician 2014;60:e272-e280.

43. Wikström K, Lindström J, Harald K, et al. Clinical and lifestylerelated risk factors for incident multimorbidity: 10-year follow-up of finnish population-based cohorts 1982-2012. Eur J Intern Med 2015;26:211-6.

44. Kuo RN, Lai MS. The influence of socio-economic status and multimorbidity patterns on healthcare costs: a six-year follow-up under a universal healthcare system. Int J Equity Health 2013;12:69.

45. Wikström K, Lindström J, Tuomilehto J, et al. Socio-economic differences in dysglycemia and lifestyle-related risk factors in the Finnish middle-aged population. Eur J Public Health $2011 ; 21: 768-74$.

46. Khanam MA, Streatfield PK, Kabir ZN, et al. Prevalence and patterns of multimorbidity among elderly people in rural Bangladesh: a cross-sectional study. $J$ Health Popul Nutr 2011;29:406.

47. Leischik R, Foshag P, Strauß M, et al. Physical activity, cardiorespiratory fitness and carotid intima thickness: sedentary occupation as risk factor for atherosclerosis and obesity. Eur Rev Med Pharmacol Sci 2015;19:3157-68.

48. Hudon C, Soubhi H, Fortin M. Relationship between multimorbidity and physical activity: secondary analysis from the Quebec health survey. BMC Public Health 2008;8:304.

49. Pache B, Vollenweider P, Waeber G, et al. Prevalence of measured and reported multimorbidity in a representative sample of the Swiss population. BMC Public Health 2015;15:164.

50. Farzadi F, Ahmadi B, Shariati B, et al. Women's health: explaining the trend in gender ratio in Iran over half a century (1956-2006). Public Health 2010;124:86-9.

51. Vosoogh Moghaddam A, Damari B, Alikhani S, et al. Health in the 5th 5 -years development plan of Iran: main challenges, general policies and strategies. Iran J Public Health 2013;42:4242.

52. Rashidian A, Karimi-Shahanjarini A, Khosravi A, et al. Iran's Multiple Indicator Demographic and Health Survey - 2010: Study protocol. Int J Prev Med 2014;5.

53. Leischik R, Dworrak B, Strauss M, et al. Plasticity of health. Ger J Med 2016;1:1-17.

54. Awofeso $\mathrm{N}$. The healthy cities approach-- reflections on a framework for improving global health. Bull World Health Organ 2003;81:222-3.

55. Healthy Cities. 2016. http://www.euro.who.int/en/health-topics/ environment-and-health/urban-health/activities/healthy-cities (access 20 March 2016).

56. O'Neill M, Simard P. Choosing indicators to evaluate healthy cities projects: a political task? Health Promot Int 2006;21:145-52.

57. Kickbusch I, Nutbeam D. Health promotion glossary. Geneva: World Health Organization, 1998. 